\title{
Acute myocardial infarction in non-cardiac critically ill patients: a clinical-pathological study
}

\section{Infarto miocardico acuto in pazienti critici non cardiologici: uno studio clinico-patologico}

\author{
Giorgio Berlot ${ }^{1}$, Antonella Vergolini1, Cristina Calderan1, \\ Rossana Bussani2, Lucio Torelli3, Umberto Lucangelo1
}

\begin{abstract}
Acute myocardial infarction in non-cardiac critically ill patients: a clinical-pathological study. G. Berlot, A. Vergolini, C. Calderan, R. Bussani, L. Torelli, U. Lucangelo.

Background: in patients admitted to the Intensive Care Unit (ICU) for non cardiac disease, the diagnosis of acute coronary syndromes can be challenging. The aim of the study was to define the rate of discrepancies concerning the diagnosis of acute myocardial infarction and to evaluate the presence of risk factors that could be helpful in identifying patients at higher risk of missed diagnosis.

Methods: we compared clinical and autopsy records of 600 critically ill patients who died in our ICU in a 10-years period. We identified patients in whom acute myocardial infarction was reported as the cause of death on the clinical records or was discovered only at post-mortem examination. These subjects were subsequently divided into two Groups: patients in Group 1 underwent diagnostic evaluation for
\end{abstract}

\begin{abstract}
acute myocardial infarction whereas those in Group 2 were not investigated for.

Results: In Group 1, a definite clinical diagnosis was reached in 11 patients $(14,7 \%)$ but remained undetermined in 37 patients $(48 \%)$. The diagnosis was totally missed in 8 patients in Group $1(10,6 \%)$ and in 20 patients of Group 2 $(26,6 \%)$. The diagnostic discrepancy was higher in septic patients, in whom the correct diagnosis of acute myocardial infarction was established at a rate lower than $50 \%$ in respect to non-septic patients.

Conclusions: Our experience strengthens the role of post-mortem examination as a source of feed-back of the overall diagnostic and therapeutic approach especially in septic patients, where the diagnostic error is more frequent.

Keywords: autopsy, diagnostic discrepancies, critically ill patients, acute myocardial infarction, sepsis.
\end{abstract}

Monaldi Arch Chest Dis 2010; 74: 164-171.

\footnotetext{
1 University of Trieste, Dept. of Anaesthesia and Intensive Care, Cattinara Hospital, Strada di Fiume 447, 34149 Trieste, Italy.

2 University of Trieste, Dept. of Pathology, Cattinara Hospital, Strada di Fiume 447, 34149 Trieste, Italy.

3 University of Trieste, Dept. of Biostatistics, Piazzale Europa 1, 34127 Trieste, Italy.
}

Corresponding author: prof. Giorgio Berlot; Dept. of Anaesthesia and Intensive Care, Cattinara Hospital; Strada di Fiume 447, I-34149 Trieste, Italy; Tel: +390403994540; Fax: +390040912278; E-mail address: berlot@inwind.it

\section{Introduction}

In patients admitted to the Intensive Care Unit (ICU) for reasons different from cardiac disease, several clinical events can cause myocardial ischemia and/or acute myocardial infarction (AMI) [1-8]: however, both conditions can be hard to diagnose using the criteria indicated by the European Society of Cardiology and American College of Cardiology, which include the increase of serum markers of myocardial damage associated with suggestive symptoms and/or electrocardiographic (ECG) changes [9]. Actually, in the critically ill patients the diagnosis can be particularly challenging since AMI-induced abnormalities, including hemodynamic instability, a reduced level of consciousness, ECG changes and elevated blood levels of cardiac enzymes can be caused also by non-cardiac events $[10,11]$. The relevance of these diagnostic difficulties is underscored by the wide range of AMI reported in non-cardiac critically ill patients, ranging from 15 to $36 \%$ [12, 13].
Taking advantage of the high rate of autopsy performed in our hospital despite a worldwide everdecreasing rate of post-mortem studies [14, 15], we compared clinical and autopsy records of a population of critically ill adult patients admitted to our ICU for non-cardiac reasons in order (a) to define the rate of discrepancies concerning the diagnosis of AMI; and (b) to evaluate the presence of risk factors that could be helpful in identifying patients at risk of missed diagnosis.

\section{Methods}

We retrospectively reviewed all the autopsies performed in patients deceased in our ICU since January 1st, 1996 to December 31st, 2007. As the study was retrospective and did not imply any intervention and/or privacy violation, the consent of the local ethics committee was deemed unnecessary. In order to limit the study to subjects without a pre-existing diagnosis of AMI, we excluded patients with post-cardiac arrest status due to coronary 
artery disease (CAD) or with the diagnosis of AMIrelated complications causing the ICU admission. Trauma, paediatric and obstetric patients were also excluded from the study, because, according to the current Italian law, the results of the autopsies of the former are not disclosed to the caring physicians and the two latter categories are treated in another hospital.

The study was conducted in two phases. The first step consisted in the identification of patients in whom (a) an AMI was reported as the cause of death on the clinical records; or (b) an AMI was discovered only at post-mortem examination by the gross examination of the heart and microscopically confirmed thereafter. Positive cases were then divided into three categories on the basis of the histological findings $[16,17]$ :

(a) Hyper acute necrosis, characterized by the presence of a marked cytoplasmatic eosinophilia, enlargement of the nucleus and apoptosis without inflammation, indicating a lesion developed 4-10 hours before death (Figure 1 and 2);

(b) Acute necrosis, whose features were a marked coagulative cell lysis and extensive interstitial inflammatory infiltration, indicating a lesion occurring $>12$ hours but $<2$ weeks before death (Figure 3);

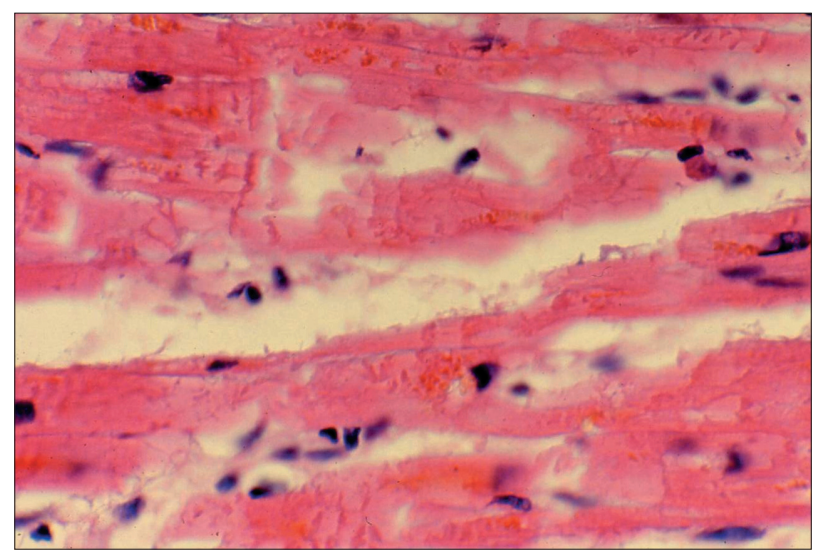

Figure 1. - H \& E, x60. Hyperacute myocardial necrosis. Hypereosinophilic cytoplasm of myocites. Nuclear picnosis and apoptosis. No inflammation.

H \& E: hematoxylin and eosin

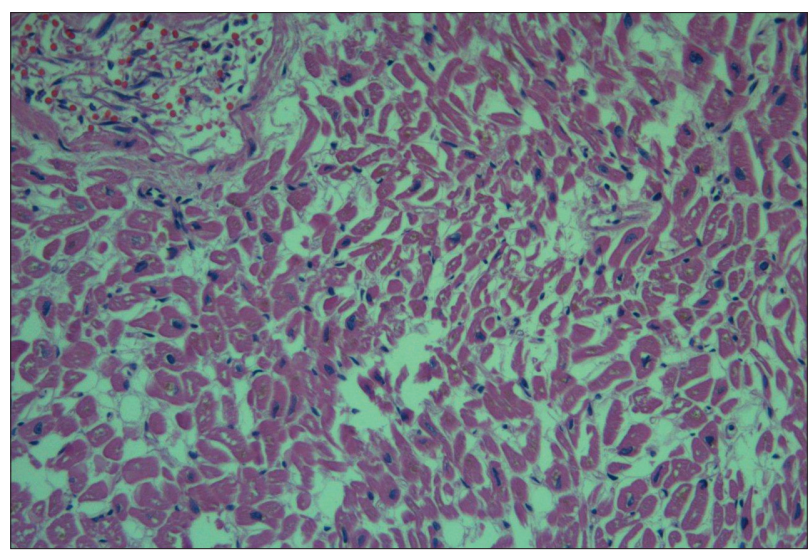

Figure 2. - H \& E, x20. Hyperacute myocardial necrosis. Evident nuclear changes (picnosis, karyolisis); interstitial edema; myocytes with eosinophilic cytoplasm. No evidence of interstitial inflammation $H \&$ E: hematoxylin and eosin (c) re-infarction if the new lesion occurred upon a previous one dating more than 6 months (Figure 4).

The second step consisted in the thorough review of the medical records of all AMI patients either at the autopsy or in whom this diagnosis was established during their ICU stay. These subjects were subsequently divided into two Groups: patients in Group 1 had undergone diagnostic evaluation for AMI whereas those in Group 2 had not been investigated for. The clinical diagnosis of AMI was based on the above described criteria [9]. A definite clinical diagnosis was established in the presence of both raised blood Troponin (Tn) levels and suggestive ECG signs, while when only one of these variables was abnormal the diagnosis was considered undetermined.

The patients' age and gender, the causes of hospital and ICU admission, the diagnostic interventions, the presence of concomitant disease, of sepsis and sepsis-related conditions $[18,19]$ and the use of cathecolamines were recorded. In case of multiple admissions, only the last one was considered.

The data are expressed as means and standard deviation (SD) for continuous variables and numbers and frequencies for nominal variables. MannWhitney test, ANOVA test and Chi-square test were used, as appropriate. A $p$ value $<.05$ was considered statistically significant.

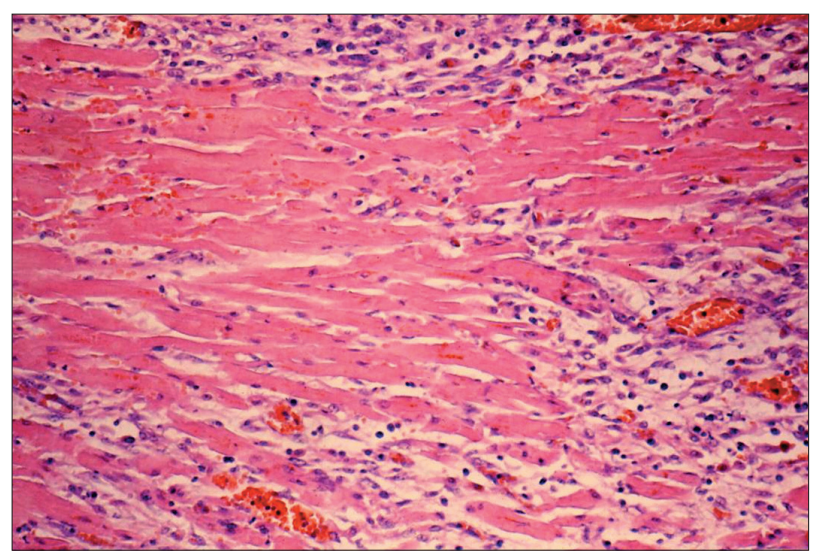

Figure 3. - H \& E, x20. Acute myocardial infarction. Diffuse coagulative myocytolysis and extensive interstitial inflammatory infiltration (neutrophils polymorphonuclear, lymphocytes and plasma cells) $\mathrm{H} \& \mathrm{E}$ : hematoxylin and eosin

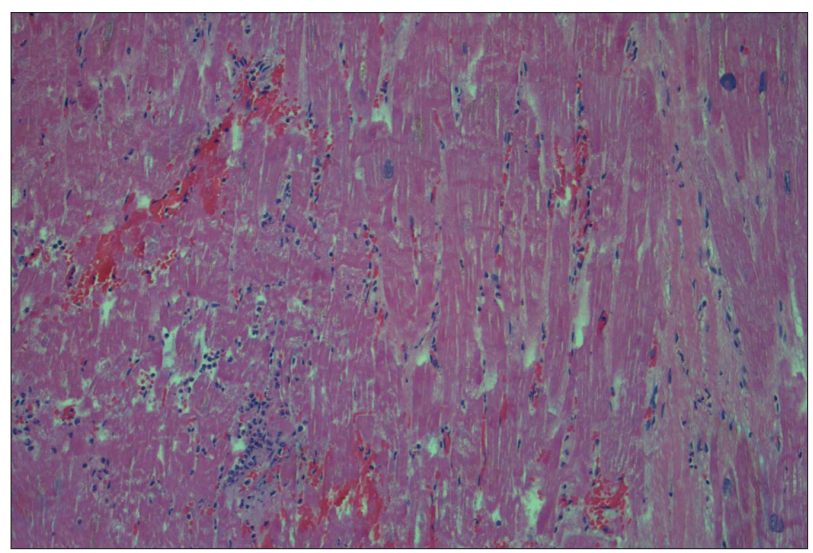

Figure 4. - Reinfarction. Scar tissue near myocardial damage (hypereosinophilic fibers, foci of coagulative myocytolis) with interstitial granulocytic inflammation 


\section{Results}

During the study period, 600 autopsies were performed. Overall, an AMI was found in 75 cases $(12,5 \%)$. Fifty-five patients $(73 \%)$ were included in Group 1 and the remaining $20(27 \%)$ in Group
2. The characteristics of patients were comparable in the two Groups, which differed only for significant higher prevalence of hypertension and dobutamine use in Group 1 (Table 1). A CAD was present in $33,3 \%$ of patients while the remaining presented either non-ischemic cardiomyopathies (e.g.

Table 1. - Patient population

\begin{tabular}{lccc}
\hline Population & Group 1 & Group 2 & p \\
\hline Patients -n (\%)- & $55(73,3)$ & $20(26,7)$ & \\
Age (median \pm SD) & $72,7 \pm 10,9$ & $68,7 \pm 10,8$ & n.s. \\
Male & $35(63,6)$ & $14(70)$ & n.s. \\
Female & $20(36,3)$ & $6(30)$ & n.s. \\
\hline
\end{tabular}

Sepsis and related conditions -n (\%)-

\begin{tabular}{lccc} 
SIRS & $3(5,4)$ & $4(20)$ & n.s. \\
sepsis & 0 & 0 & n.s. \\
severe sepsis & $4(7,2)$ & 0 & n.s. \\
septic shock & $17(30,9)$ & $9(45)$ & n.s. \\
non septic shock & $21(38,1)$ & $6(30)$ & n.s. \\
\hline
\end{tabular}

LOS (days (median \pm SD)

$\begin{array}{lccc}\text { LOS }_{\text {preICU }} & 12,3 \pm 16,7 & 22,7 \pm 34,6 & \text { n.s. } \\ \text { LOS ICU } & 5,3 \pm 5,5 & 8,5 \pm 12,3 & \text { n.s. }\end{array}$

Reason for hospital admission -n (\%)-

Cardiac arrest/cardiogenic shock

$5,3 \pm 5,5$

$8,5 \pm 12,3$

n.s.

Medical disease

$4(7,2)$

$1(5)$

$18(32,7)$

$10(50)$

n.s.

Planned surgery

$6(10,9)$

$1(5)$

n.s.

Urgent/emergency surgery

$25(45,4)$

8 (40)

n.s.

n.s.

$2(3,6)$

0

Septic shock

$8(14,5)$

$18(32,7)$

$3(5,4)$

16 (29)

$10(18,1)$

$18(32,7)$

$31(56,3)$

$28(50,9)$

$15(27,2)$

$2(3,6)$

$7(12,7)$

$9(16,3)$

5 (9)

$16(29)$

$6(10,9)$

21 (38)

34 (62)

Non-ischemic cardiopathy/no cardiopathy

RRT -n (\%)-

$6(10,9)$

23(41,8)

29(52,7)

29(52,7)

(10)

12(60)

10(50)

9 (45)

0

5 (25)

5 (25)

n.s.

Cardiovascular agents -n (\%)-

Dopamine

Norepinephrine

4 (20)

$6(30)$

9 (45)

3 (15)

0

0

$1(5)$

2 (10)

7 (35)

1 (5)

4 (20)

$16(80)$

$1(5)$

n.s.

n.s.

n.s.

n.s.

n.s.

CAD: coronary artery disease; COPD: Chronic obstructive pulmonary Disease; LOS: length of stay; RRT: renal replacement therapy; SIRS: Systemic Inflammatory Response Syndrome 
toxic-metabolic, dilatative etc) or no lesions at all. Comparing the two groups, the prevalence of CAD was slightly higher in Group 1 than in Group 2 (respectively $38 \%$ vs. 20\%). Microscopic findings confirmed an AMI in $87 \%$ of cases in Group 1 and in $95 \%$ in Group 2. Acute necrosis was the major histological finding in Group 1, while hyperacute necrosis was more frequently found in Group 2 (Table 2).

In Group 1, a definite clinical diagnosis was reached in 11 patients $(14,7 \%)$ but remained undetermined in 37 patients $(48 \%)$. The diagnosis was totally missed in 8 patients in Group $1(10,6 \%)$ and in 20 patients of Group $2(26,6 \%)$.

The whole study population was then subdivided according to the presence of sepsis (Table 3). The diagnosis of sepsis and sepsis-related conditions was made on the basis of the commonly used criteria [18, 19]. Septic patients had a significantly lower mean age, were more frequently admitted to ICU for a

\begin{tabular}{lccc} 
Table 2. - Histological findings & & \\
\hline Findings & Group 1 & Group 2 & p \\
\hline Hyperacute necrosis & $16(29 \%)$ & $8(40 \%)$ & n.s. \\
\hline Acute necrosis & $24(44 \%)$ & $(25 \%)$ & n.s. \\
\hline Reinfarction & $8(14 \%)$ & $6(30 \%)$ & n.s. \\
\hline None & $7(13 \%)$ & $1(5 \%)$ & n.s. \\
\hline
\end{tabular}

medical reason, had a lower prevalence of cardiovascular risk factors, had a lower mean serum Tn level and showed less frequently ischemic ECG changes. No difference was found in the prevalence of CAD or non-ischemic cardiomyopathy /no cardiomyopathy between septic and non septic patients. Moreover, AMI-addressed investigations were performed less frequently in septic than in non septic patients $(65,4 \%$ and $78,7 \%$, respectively; $p<0,05)$. Septic patients had higher prevalence of hyperacute necrosis while acute necrosis was more frequent in non septic patients (Figure 5). In both Groups the pathological findings were subsequently correlated with the presence of sepsis and related condition. Both acute necrosis and re-infarctions were uniformly distributed between the two groups (Table 4).

In Group 1, the ECG revealed the presence of acute ischemic changes in $30,9 \%$ of patients. Up to $70 \%$ of patients in Group 2 did not have an ECG, while in the remaining $30 \%$ the ECG was not indicative. Echocardiographic evaluation was performed in $32,8 \%$ and $15 \%$ of patients in Group 1 and Group 2, respectively (Table 5).

\section{Discussion}

In the clinical practice, the use of 12-lead ECG in combination with the repeated measurements of blood Tn levels constitute the standard approach for the diagnosis of AMI in patients with suggestive symptoms [20]. However, whereas this diagnosis can be relatively straightforward in the absence of con-

Table 3. - Characteristics of septic and non septic patients

\begin{tabular}{|c|c|c|c|}
\hline Variable & Septic patients & Non septic patients & $\mathbf{p}$ \\
\hline $\mathrm{n}^{\circ}(\%)$ & $26(34,7 \%)$ & $49(65,3 \%)$ & \\
\hline Age $($ mean $\pm \mathrm{SD})$ & $67 \pm 12$ & $74 \pm 10$ & 0.009 \\
\hline \multicolumn{4}{|l|}{$\operatorname{LOS}($ days) $($ mean \pm SD) } \\
\hline Pre ICU & $23 \pm 33$ & $11 \pm 13,4$ & ns \\
\hline ICU & $8 \pm 10,5$ & $5 \pm 6$ & ns \\
\hline \multicolumn{4}{|l|}{ Risk factors $(\%)$} \\
\hline Diabetes & 23 & 32 & ns \\
\hline hypertension & 61,5 & 44,6 & ns \\
\hline Heart disease & 34,6 & 57,4 & 0.05 \\
\hline COPD & 7,6 & 34 & 0.012 \\
\hline cardiac failure & 3,8 & 12,7 & ns \\
\hline renal failure & 11,5 & 12,7 & ns \\
\hline CAD & 35 & 33 & ns \\
\hline Non-ischemic cardiopathy/no cardiopathy & 65 & 67 & ns \\
\hline RRT (\%) & 19 & 4 & 0.037 \\
\hline \multicolumn{4}{|l|}{ AMI-Targeted investigations } \\
\hline Troponin $(\mathrm{mcg} / \mathrm{ml})($ mean $\pm \mathrm{SD})$ & $9,4 \pm 16,5$ & $17,6 \pm 42,5$ & ns \\
\hline ECG acute ischemic changes (\%) & 15,4 & 27,6 & ns \\
\hline Echocardiography $(\%)$ & 19,23 & 63,8 & ns \\
\hline
\end{tabular}

SIRS: Systemic Inflammatory Response Syndrome; LOS: length of stay; COPD: Chronic Obstructive Pulmonary Disease; RRT: renal replacement therapy; CAD: coronary artery disease 


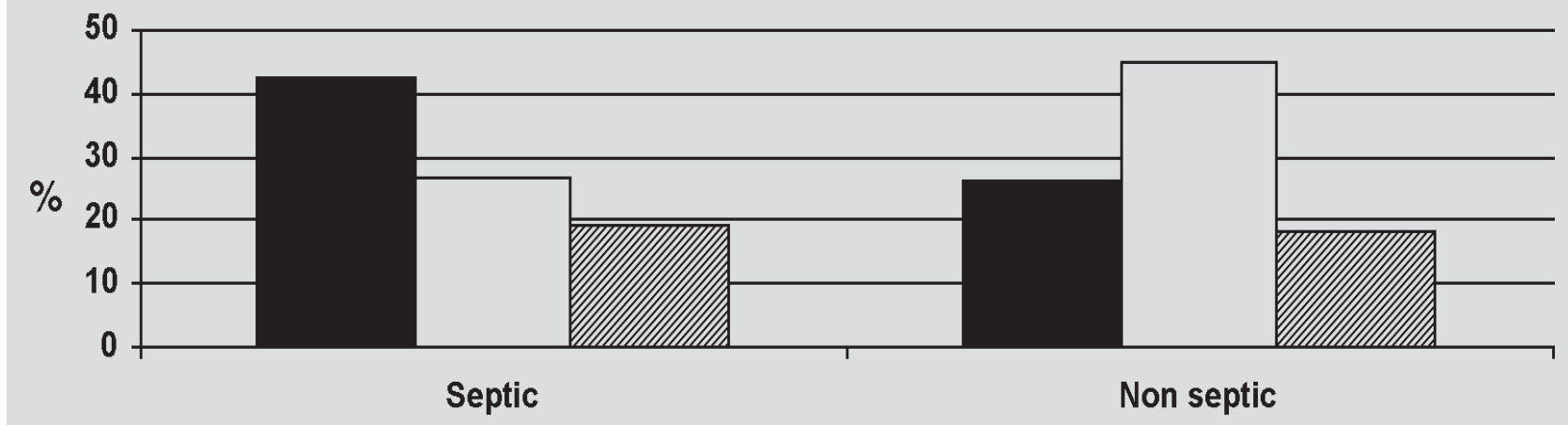

Figure 5. - Histologic findings in septic and non septic patients

Legend: black bars: hyperacute necrosis; white bars: acute necrosis; dashed bars; reinfarction; p: n.s. for all groups.

Table 4. - Histologic findings in shocked patients

\begin{tabular}{ccccccc}
\hline & \multicolumn{2}{c}{ Hyperacute necrosis } & \multicolumn{2}{c}{ Acute necrosis } & \multicolumn{2}{c}{ Reinfarction } \\
\hline Non septic & Septic & Non septic & Septic & Non septic & Septic \\
\hline Group 1 & $8(21)$ & $8(47)$ & $19(50)$ & $5(29,4)$ & $6(15,8)$ & $2(11,8)$ \\
\hline Group 2 & $5(45,4)$ & $3(33)$ & $3(27,3)$ & $2(23)$ & $3(27,3)$ & $3(33)$ \\
\hline
\end{tabular}

Table 5. - AMI-directed investigations

\begin{tabular}{lcc}
\hline Investigation & Group 1 & Group 2 \\
\hline Enzymes (mean \pm SD) & & \\
\hline Troponin $(\mathrm{mcg} / \mathrm{ml})$ & $15,8 \pm 37,1$ & Not measured \\
CPK-MB $(\mathrm{u} / \mathrm{L})$ & $96,8 \pm 225$ & 0 \\
\hline ECG Findings -n(\%)- & & $14(70)$ \\
\hline - not recorded & $9(16,3)$ & $6(30)$ \\
- not interpreted & $15(27,2)$ & 0 \\
- normal & $1(1,8)$ & 0 \\
- former ischemic changes & $2(3,6)$ & 0 \\
- non ischemic changes & $11(20)$ & 0 \\
- acute ischemic changes & $17(30,9)$ & $17(85)$ \\
\hline US findings -n(\%)- & & $3(15)$ \\
\hline - not performed & $37(67,2)$ & 0 \\
- normal/mild alterations as left ventricular hypertrophy & $6(10,9)$ & 0 \\
- moderate alteration of ventricular kinetics; normal EF & $6(10,9)$ & $6(10,9)$ \\
- severe alteration of left ventricular kinetics/reduction EF & & \\
\hline
\end{tabular}

$\mathrm{US}=$ echocardiography; $\mathrm{EF}=$ ejection fraction

founding factors, in critically ill patients admitted to the ICU for non-cardiac reasons it can become elusive. In our patients found positive to AMI at the post-mortem examination, a definite clinical diagnosis could be established in a minority of them (roughly 15\%), whereas in the remaining patients the diagnosis remained doubt or was totally missed. False negative cases were present as well, since the histological examination did not show any compatible lesion in 8 patients diagnosed AMI-positive on the basis of the ECG and the cardiac enzymes. Different factors account for these discrepancies. First, the AMI-related hemodynamic derangements can be easily ascribed to causes different from myocardial ischemia, including hypovolemia, mechanical ventilation etc [21]. Second, the conventional 12-lead 
ECG can be misleading as it can be influenced by non-ischemic conditions, such as certain therapies and the presence of acid-base and electrolytes disorders [10]. Third, the blood levels of cardiac enzymes can be elevated also in the absence of cardiac ischemia in $15-70 \%$ of critically ill patients without CAD [1, 22, 23]. Actually, other investigators [24], demonstrated that histological examination revealed contraction band necrosis in only half of patients with a elevated pre-mortem Tn levels, suggesting that its release does not necessarily indicate myocardial cell necrosis. Indeed, elevated serum Tn levels in septic patients can be seen even with increased coronary blood flow, a decreased extraction of oxygen across the coronary circulation and maintenance of normal high-energy phosphate levels [25-27]. Finally, most ICU patients are unable to report symptoms of cardiac ischemia. Independently from all these circumstances, the implementation in se and per se of AMI-directed investigations can be hard to decide on the basis of the clinical characteristics: in our patients, no significant differences were demonstrated between the two groups, including gender, age, prevalence of shock, acid-base abnormalities and $\mathrm{PaO}_{2} / \mathrm{FIO}_{2}$ ratio; only a higher prevalence of hypertension and the administration of dobutamine were more frequent in our patients fully investigated for AMI. Moreover, it appears that concomitant conditions do not influence the incidence of false positive cases, as the rate of patients with a clinical diagnosis of AMI, but without corresponding autopsy findings, was the same in septic and non septic patients. We believe that the lesser number of AMI-directed investigations performed in septic patients can be ascribed to a reduced index of suspicion toward its presence, as the hemodynamic derangements were ascribed to sepsis. Although not statistically different, there was a greater prevalence of acute necrosis in Group $1(44 \%)$, whereas hyper acute necrosis $(40 \%)$ and reinfarctions $(30 \%)$ predominated in Group 2. A more in-detail analysis of the characteristics of the patients with acute necrosis shows that cardiovascular risk factors and non-septic shock were more frequent in Group 1 than in Group 2, where septic shock is more prevalent. The same situation is found in patients with reinfarctions, where the prevalence of septic shock is higher in Group 2 than in Group 1. Actually, a large part of septic patients had an undetermined diagnosis (46\%), while the AMI was totally missed in other $46 \%$ of cases; it is worthwhile to remind that this rate is higher than that reported in the overall population (37\%). Myocardial dysfunction frequently accompanies septic shock, evidenced by biventricular dilatation and reduced ejection fraction [28]. Nevertheless, patients with myocardial dysfunction have significant higher mortality $(70 \%)$ compared with septic patients without cardiovascular impairment $(20 \%)[29,30]$. There is currently no evidence supporting global ischemia as an underling cause of this condition [31]. Actually, many investigations suggest that circulating factors, such as cytokines (TNF- $\alpha$, IL- $1 \beta$ ) and nitric oxide $[28,31,32]$, and other mechanisms, such as mitochondrial dysfunction or the down regulation of the expression of heat-shock protein 20 (Hsp20) [33] can account for this phenomenon. Anyway, in patients with CAD, regional myocardial ischemia can certainly occur, further aggravated by the pro-coagulant actions exerted by many sepsis mediators and the prolonged exposition to high levels of either endogenous or exogenous cathecholamines [31, 34]. In our study, despite lower levels of blood Tn and lower rate of ischemic ECG signs, septic shock patients presented an incidence of hyper acute lesions involving almost the entire left ventricle in close to $50 \%$ of cases. Indeed it has been demonstrated that elevated Tn levels in septic patient reflect higher disease severity, myocardial dysfunction and worse prognosis [31]. It appears that the missed or undetermined diagnosis can be at least partially explained by this kind of lesion, as hyperacute necrosis occurred within 4-10 hours from death, while the first elevation of serum Tn occurs after 3-4 hours from the acute event [35] and is preceded by ECG changes [36], thus leaving a timeframe in which no alterations could be detected.

This study highlighted the importance of postmortem examination as an important tool in auditing clinical practice and diagnostic performance. Actually, despite all the advances in the diagnostic procedures, the rate of discrepancies between clinical and autopsy diagnoses remains constant [37, 38], ranging from $6 \%$ to $40 \%$ [37, 39, 40]. Critically ill patients are particularly at risk, due to the intrinsic difficulty in achieving a complete history, the rapid evolution of the disease(s) and the high incidence of confounding factors [41]. Not surprisingly, some authors indicated the failure to recognize AMI as the main missed diagnosis [42].

In conclusion, in patients admitted to the ICU for non-cardiac reasons, the identification of those at risk for AMI is difficult, mainly due to the concomitant conditions that can prevent an appropriate screening. In our study, the diagnostic discrepancy was higher in septic patients, in whom the correct diagnosis of AMI was established at a rate lower than $50 \%$ of cases as compared with non-septic patients. This can be at least partially explained either by the greater occurrence of hyperacute lesions which prevented the caring physician to implement an AMI-directed diagnostic workup or by the attribution of cardiovascular symptoms, including arterial hypotension, tachycardia etc, to the action of sepsis-associated vasodilatation and myocardial depressant factors. Our experience also strengthens the role of post-mortem examination especially in critically ill patients as a source of feed-back of the overall diagnostic and therapeutic approach [14, 15, 39, 40]. The identification of this high-risk, under-diagnosed class of patients should rises the attention towards a more accurate monitoring, diagnosis and possibly treatment of these patients, thus improving their prognosis.

\section{Riassunto}

Background: nei pazienti ammessi presso l'Unità di Terapia Intensiva per malattie non cardiache la diagnosi di sindrome coronarica acuta può risultare difficoltosa. Lo scopo dello studio è definire il tasso di discrepanza riguardante la diagnosi di infarto miocardio acuto e valutare la pre- 
senza di fattori di rischio potenzialmente utili nell'identificare $i$ pazienti a maggior rischio di omessa diagnosi.

Metodi: abbiamo comparato le cartelle cliniche e i rilievi autoptici di 600 pazienti critici morti presso la nostra Terapia Intensiva in un periodo di dieci anni. Abbiamo identificato i pazienti in cui un infarto miocardico acuto veniva riportato come causa del decesso nella cartella clinica oppure veniva scoperto soltanto all' analisi autoptica. Questi soggetti sono stati poi suddivisi in due gruppi: al gruppo 1 sono stati assegnati i pazienti sottoposti a valutazione diagnostica per infarto acuto del miocardio, mentre al gruppo 2 i pazienti non sottopost $i$ ad alcun accertamento.

Risultati: nel gruppo 1 una diagnosi definitiva veniva raggiunta in 11 pazienti $(14,7 \%)$ mentre rimaneva indeterminata in 37 pazienti (48\%). La diagnosi veniva completamente omessa in 8 pazienti del gruppo $1(10,6 \%)$ e in 20 pazienti del Gruppo 2 (26,6\%). La discrepanza diagnostica era maggiore nei pazienti settici, dove la diagnosi corretta di infarto acuto del miocardio era stabilita ad un tasso inferiore al 50\% rispetto ai pazienti non settici.

Conclusioni: la nostra esperienza rafforza il ruolo dell' esame autoptico dei pazienti come feedback del complesso approccio diagnostico e terapeutico soprattutto nei pazienti settici, dove l'errore diagnostico è più frequente.

\section{LIST OF ABBREVIATIONS/ ACRONYMS}

(in order of appearance in the text)

ICU: Intensive Care Unit

AMI: acute myocardial infarction

ECG: electrocardiographic

CAD: coronary artery disease

Tn: troponin

SD: standard deviation

$\mathrm{PaO}_{2} / \mathrm{FIO}_{2}$ ratio: ratio of partial pressure of arterial $\mathrm{O}_{2}$ to the fraction of inspired $\mathrm{O}_{2}$

Aknowledgment: The authors declare that they have no conflict of interest.

\section{References}

1. Charlson ME, MacKenzie CR, Gold JP et al. The preoperative and intraoperative hemodynamic predictors of postoperative myocardial infarction or ischemia in patients undergoing noncardiac surgery. Ann Surg 1989; 210: 637-648.

2. Nelson AH, Browner WS, Hollenberg M et al. Relationship between postoperative anemia and cardiac morbidity in high-risk vascular patients in the intensive care unit. Crit Care Med 1993; 21: 860-866.

3. Brathwaite D, Weissman C. The new onset of atrial arrhythmias following major noncardiothoracic surgery is associated with increased mortality. Chest 1998; 114: 462-468.

4. Hurford WE, Lynch KE, Strauss HW, Lowenstein E et al. Myocardial perfusion as assessed by thallium-201 scintigraphy during the discontinuation of mechanical ventilation in ventilatory-dependent patients. Anesthesiology 1991; 74: 1007-1016.

5. Lemaire F, Teboul J, Cinotti L, et al. Acute left ventricular disfunction during unsuccessful weaning from mechanical ventilation. Anesthesiology 1988; 69:171-179.
6. Abalos A, Leibowitz AB, Distefano D, et al. Myocardial ischemia during the weaning period. Am J Crit Care 1992; 1: 32-36.

7. Chatila W, Ani S, Guaglianon D, et al. Cardiac ischemia during weaning from mechanical ventilation. Chest 1996; 109: 1577-1583.

8. Hurford WE, Favorito F. Association of myocardial ischemia with failure to wean from mechanical ventilation. Crit Care Med 1995; 23: 1475-1480.

9. Alpert JS, Thygesen K, Antman E, et al. Myocardial infarction redefined-a consensus document of the Joint European Society of Cardiology/American College f Cardiology Committee for the ridefinition of myocardial infarction. J Am Coll Cardiol 2000; 36: 959-969.

10. Noble JS, Reid AM, Jordan LVM, et al. Troponin I and myocardial injury in the ICU. Br J Anaesth 1999; 82: 41-46.

11. Landesberg G, Vesselov Y, Einav S, et al. Myocardial ischemia, cardiac troponin, and long term survival pf highcardiac risk critically ill intensive care unit patients. Crit Care Med 2005; 33: 1281-1287.

12. Guest TM, Ramanathan AV, Tuteur PG, et al. Myocardial injury in critically patients. A frequently unrecognised complication. JAMA 1995; 273: 1945-1949.

13. Lim W, Holinski P, Dvereaux PJ, et al. Detecting myocardial infarction in critical illness using screening troponin measurements and ECG recordings. Crit Care 2008; 12: R36.

14. Baker PB, Zarbo RJ, Howanitz PJ. Quality assurance of autopsy face sheet reporting, final autopsy report turnaround time, and autopsy rates: a College of American Pathologists Q-Probes study of 10,003 autopsies from 418 institutions. Arch Pathol Lab Med 1996; 120: 10031008.

15. Start RD, Firth JA, Macgillivray F, Cross SS. Have declining clinical necropsy rates reduced the contribution of necropsy to medical research? J Clin Pathol 1995; 48: 402-404.

16. Silver D. Ischemic disease of the myocardium and its complications in: Cardiovascular Pathology, $2^{\text {nd }}$ Edition. Edited by Churchill Livingstone. Inc, 1991: 686-689.

17. Lodge-Patch I. The ageing of cardiac infarcts and its influence on cardiac rupture. Br Heart J 1951; 13:37.

18. American College of Chest Physicians-Society of Critical Care Medicine Consensus Conference: Definitions for sepsis and organ failure and guidelines for the use of innovative therapies in sepsis. Crit Care Med 1992; 328: 864-875.

19. Levy MM, Fink MP, Marshall JC, et al. SCC/ESICM/ ACCP/ATS/SIS International Sepsis Definitions Conference. Crit Care Med 2001; 31: 1250-1256.

20. Lim W, Qushmaq I, Cook DJ, et al. Elevated troponin and myocardial infarction in the intensive care unit: a prospective study. Crit Care 2005; 9: R636-R644.

21. Chockalingam A, Mehra A, Dorairajan S, Dellsperger KC: Acute left ventricular dysfunction in the critically ill. Chest 2010; 138: 198-207.

22. Spies C, Haude V, Fitzner R, et al. Serum cardiac troponin $\mathrm{T}$ as a prognostic marker of myocardial injury in early sepsis. Chest 1998; 113: 1055-1063.

23. Arlati S, Brenna S, Prencipe L, et al. Myocardial necrosis in ICU patients with acute non cardiac disease: a prospective study. Intensive Care Med 2000; 26: 31-37.

24. Ver Elst KM, Spapen HD, Nguyen DN, et al. Cardiac troponins I and T are biological markers of left ventricular dysfunction in septic shock. Clin Chem 2000; 46: 650-657.

25. Ognibene FP, Parker MM, Natanson C, et al. Depressed left ventricular performance. Response to volume infusion in patients with sepsis and septic shock. Chest 1988; 93: 903-910.

26. Cunnion RE, Schaer GL, Parker MM, et al. The coronary circulation in human septic shock. Circulation 1986; 73: 637-644. 
27. Dhainaut JF, Huyghebaert MF, Monsallier JF, et al. Coronary hemodynamics and myocardial metabolism of lactate, free fatty acids, glucose, and ketones in patients with septic shock. Circulation 1987; 75: 533-541.

28. Court O, Kumar A, Parrillo JE et al. Clinical Review: myocardial depression in sepsis and septic shock. Crit Care 2002; 6: 500-508 (DOI 10.1186/cc1822).

29. Parrillo JE, Parker MM, Natanson C, et al. Septic shock in humans: Advances in the understanding of pathogenesis, cardiovascular dysfunction, and therapy. Ann Intern Med 1990; 113: 227-242.

30. Blanco J, Muriel-Bombin A, Sagredo V, et al. Incidence, organ dysfunction and mortality in severe sepsis: a Spanish multicentre study. Crit Care 2008 12: R158.

31. Merx MW, Weber C. Sepsis and Heart. Circulation 2007; 116: 793-802.

32. Zanotti-Cavazzoni SL, Hollenberg SM. Cardiac dysfunction in severe sepsis and septic shock. Curr Opin Crit Care 2009; 15: 392-397.

33. Wang X, Zingarelli B, O'Connor M, et al. Overexpression of Hsp20prevents endotoxin-induced myocardial dysfunction and apoptosis via inhibition of NF- $\mathrm{KB}$ activation. J Mol Cell Cardiol 2009; 47: 382-390.

34. Bernard GR, Vincent JL, Laterre PF, et al. Efficacy and safety of recombinant human activated protein $\mathrm{C}$ for severe sepsis. N Engl J Med 2005; 353: 699-709.
35. Bertinchant JP, Larue C, Pernel I et al. Release kinetics of serum cardiac troponin I in ischemic myocardial injury. Clin Biochem 1996; 29: 587-594.

36. Thygesen K, Alpert JS, White HD et al. Universal definition of myocardial infarction. Eur Heart $J$ 2007; 28: 2525-2538.

37. Goldman L, Sayson R, Robbins S, Cohn LH, Bettmann $\mathrm{M}$, Weisberg M. The value of the autopsy in three medical eras. N Engl J Med 1983; 308: 1000-1005.

38. Goldman L. Diagnostic advances vs the value of the autopsy: 1912-1980. Arch Pathol Lab Med 1984; 108: 501-505.

39. Blosser, Sandralee A, Zimmerman H, Stauffer JL. Do autopsies of critically ill patients reveal important findings that were clinically undetected? Crit Care Med 1998; 26(8): 1332-1336.

40. Fernandez-Segoviano P, Esteban A, et al. Autopsy as quality assurance in the intensive acre unit. Crit Care Med 1988; 16: 683-685.

41. Combes A, Mokhtari M, Couvelard A, et al. Clinical and autopsy diagnoses in the intensive care unit. Arch Intern Med 2004; 164: 389-392.

42. Perkins GD, McAuley DF, Davies S, Gao F. Discrepancies between clinical and postmortem diagnoses in critically ill patients: an observational study. Crit Care 2003; 7: R129-R132. 